\title{
Persistence of Eosinophilic Asthma Endotype and Clinical Outcomes: A Real-World Observational
} Study

\author{
Trung N Tran' \\ Marjan Kerkhof ${ }^{2}$ \\ Victoria Carter ${ }^{3,4}$ \\ David B Price (iD) $3-5$ \\ 'Global Medicine Development, \\ AstraZeneca, Gaithersburg, MD, USA; \\ ${ }^{2}$ Mescio Research, Blauwestad, the \\ Netherlands; ${ }^{3}$ Observational and \\ Pragmatic Research Institute, Singapore; \\ ${ }^{4}$ Optimum Patient Care, Cambridge, UK; \\ ${ }^{5}$ Division of Applied Health Sciences, \\ Centre of Academic Primary Care, \\ University of Aberdeen, Aberdeen, UK
}

Correspondence: Trung N Tran Global Medicine Development, AstraZeneca, One Medlmmune Way, Gaithersburg, MD, 20878, USA Tel + I-30I-398-5406

Email trung.tranI@astrazeneca.com

\begin{abstract}
Purpose: Eosinophil count elevations are predictive of adverse outcomes in patients with asthma, yet little is known regarding longitudinal eosinophil patterns and their association with clinical outcomes. The goal of this study was to assess associations between longitudinal persistence of eosinophil elevations and both clinical outcomes and health care resource utilization (HCRU).
\end{abstract}

Methods: Data were extracted from 2 databases in the United Kingdom. Patients included were aged $\geq 13$ years, had active asthma, and had $\geq 3$ blood eosinophil count (BEC) recordings. Patients were categorized by BEC as: never high (all BEC $\leq 300$ cells $/ \mu \mathrm{L}$ ), intermittently high $(\geq 1 \mathrm{BEC}>300$ cells $/ \mu \mathrm{L}$ but $<75 \%$ of $\mathrm{BEC}>300$ cells $/ \mu \mathrm{L})$, or persistently high ( $\geq 75 \%$ of $\mathrm{BEC}>300$ cells $/ \mu \mathrm{L}$ ). Asthma exacerbations, asthma control (risk domain, overall, and full), and HCRU were evaluated for 12 months after the last BEC.

Results: The study population comprised 148,021 patients. Persistently high, intermittently high, and never high eosinophil patterns were detected in $13.6 \%, 40.5 \%$, and $45.9 \%$ of patients, respectively. Patients with $\geq 1$ elevated BEC were at greater risk for severe asthma exacerbations, regardless of whether the elevation was persistent (rate ratio [RR]: 1.28 [95\% CI 1.24-1.33]; $P<0.001$ ) or intermittent (RR: 1.24 [95\% CI 1.21-1.27]; $P<0.001$ ), compared with patients with no eosinophil elevations. Full asthma control was achieved by $<25 \%$ of patients across eosinophil pattern groups, and HCRU did not appreciably differ, although patients with persistently high BEC had the shortest hospital stay duration among the groups.

Conclusion: These data suggest that elevated blood eosinophils, regardless of persistency, signify increased risk of severe asthma exacerbations.

Keywords: asthma control, asthma exacerbation, biomarker, eosinophilia, phenotype, type 2 inflammation

\section{Introduction}

Despite the availability of multiple effective treatment options, many patients with asthma do not achieve adequate symptom control and are at elevated risk of flareups (exacerbations). ${ }^{1-3}$ Exacerbations can be life-threatening and contribute to disease-related morbidity, impaired health-related quality of life, progressive loss of lung function, and higher health care resource utilization (HCRU). ${ }^{4,5}$ Moreover, standard treatment of exacerbations involves oral corticosteroids (OCS), which are associated with risk of acute and chronic adverse events as well as increased HCRU and costs. ${ }^{6,7}$ Characterizing patient-related and clinical parameters that are 
associated with uncontrolled asthma and exacerbation risk has the potential to improve outcomes by identifying patients who require additional monitoring and therapeutic intervention. ${ }^{8-10}$ Moreover, understanding asthma etiology at the individual level enhances the ability to implement targeted treatment, ${ }^{1,11}$ thereby augmenting the likelihood of achieving asthma control.

Asthma is not a monolithic condition, rather it is a heterogeneous disease with varied etiologic underpinnings. ${ }^{2,11}$ Eosinophil elevations measured in sputum or blood denote a particular asthma endotype, eosinophilic asthma, which is driven by eosinophilic airway inflammation. ${ }^{2,11,12}$ High blood eosinophil counts (BECs) are linked to multiple adverse outcomes in patients with asthma, including increased risk for exacerbations, severe exacerbations, asthma-related hospital readmissions, and poor asthma control. ${ }^{13-19}$ In an historical cohort of patients with asthma from the United Kingdom (UK), a BEC $>400$ cells $/ \mu \mathrm{L}$ conferred a $42 \%$ greater risk of severe exacerbations, a $28 \%$ greater risk of acute respiratory events, and a $26 \%$ lower likelihood of achieving asthma control during a 1-year follow-up period compared with patients whose BECs were $\leq 400$ cells/ $\mu \mathrm{L}$. $^{15}$ Moreover, exacerbation rates demonstrated a dose-response relationship with BECs starting at a reference category of $\leq 200$ cells $/ \mu \mathrm{L}$. The comparatively small proportion of patients with severe, uncontrolled eosinophilic asthma accounts for a disproportionate share of asthma-related HCRU and costs. ${ }^{20,21}$ In a population-based analysis conducted in the UK, patients with severe, uncontrolled, eosinophilic asthma comprised $<1 \%$ of the study population, yet accounted for 2.5 to 7.6 times greater HCRU and direct asthma-related costs than the general population. $^{21}$

In clinical practice, BEC assessments for the identification of eosinophilic asthma are infrequently considered and, when applied, are often limited to a single time point. This approach may provide an incomplete picture because BEC levels are not fixed over time. ${ }^{22-26}$ Indeed, eosinophil counts in sputum or blood samples of patients with asthma have been shown to vary appreciably in sequential measurements. ${ }^{22,23,25}$ Few studies, particularly those derived from real-world data, have parsed asthma endotypes by longitudinal persistence of BEC elevations, and it is not known whether persistence of BEC elevations is associated with health outcomes. This study was performed to characterize patients with varying degrees of persistence in BEC elevation and to assess the association of eosinophil elevation patterns with clinical outcomes and HCRU in patients with asthma.

\section{Methods}

\section{Data Source and Study Design}

Data were extracted from the Optimum Patient Care Research Database (OPCRD) and the Clinical Practice Research Datalink (CPRD) GOLD database. OPCRD comprises data obtained through the Optimum Patient Care Quality Improvement services, which contains information from both anonymized electronic medical records (EMRs) and patient responses to disease-specific questionnaires. At data extraction, OPCRD contained data for approximately 10 million patients from more than 700 practices in the UK. CPRD GOLD is a primary care database of anonymized medical records that includes data for more than 11 million patients from 674 general practices in the $\mathrm{UK}^{27}$ Data obtained from CPRD were limited to patients whose records could be linked to Hospital Episode Statistics, a comprehensive source for hospital admission and outpatient HCRU data. Patientlevel data from OPCRD and CRPD are de-identified at the source, and patients have the option to opt-out of sharing their health information.

Baseline data represented the 12 months prior to the index date, defined as the most recent BEC measurement for which there were $\geq 12$ months of subsequent outcomes data (Figure 1). Asthma outcomes and HCRU were evaluated for 12 months after the index date (the outcome year). The year of the index date for patients included in the data sets ranged from 2006 to 2018.

\section{Study Population}

For inclusion in the study, patients were required to be aged $\geq 13$ years on the index date and have: a diagnostic code for asthma recorded at any time that was not followed by a code that asthma was resolved; $\geq 3$ BECs recorded after the date of first asthma diagnosis; active asthma, defined as $\geq 1$ prescription for an inhaler containing an inhaled corticosteroid (ICS) or a short-acting $\beta 2$-agonist (SABA) in the 12 months before the index date; and continuous EMR data for 12 months prior to and 12 months after the index date. Patients were excluded if they had a diagnosis of chronic lower respiratory disease other than asthma or chronic obstructive pulmonary disease (COPD) or if there was uncertain information regarding the age of asthma onset. Age of asthma onset was 


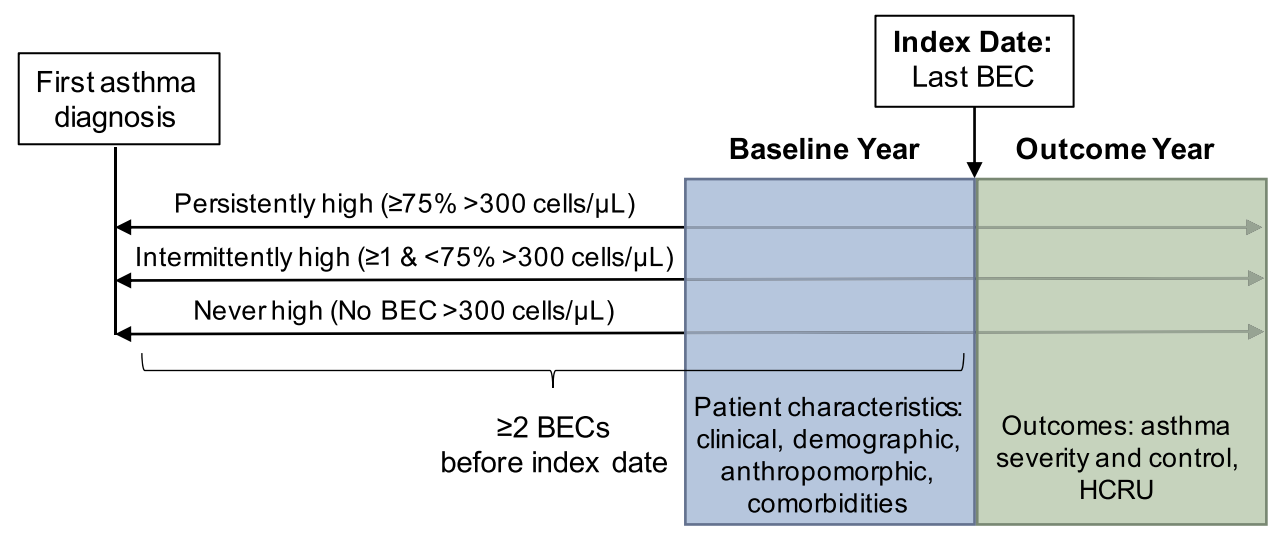

Figure I Study design. Patients were categorized as persistently high, intermittently high, or never high based on blood eosinophil counts (BECs) from the first asthma diagnosis to the index date. The index date was the date of the last BEC with at least 12 months' outcome data and without prescriptions for oral corticosteroids or antiinterleukin-5 therapy in the prior 4 weeks. The baseline and outcome years were I year prior to and I year after the index date.

Abbreviation: HCRU, health care resource utilization.

defined as first recording of asthma diagnosis dated in the first 3 years of electronic medical recording or in the fourth or fifth year of electronic medical recording not preceded or followed by an inhaler treatment prescription within 90 days after that date.

\section{Measurements and Outcomes Blood Eosinophil Counts}

Patients were categorized by longitudinal patterns of BEC elevations as: never high (all BECs $\leq 300$ cells $/ \mu \mathrm{L}$ ), intermittently high ( $\geq 1$ BEC $>300$ cells $/ \mu \mathrm{L}$ but $<75 \%$ of BECs $>300$ cells $/ \mu \mathrm{L}$ ), or persistently high ( $\geq 75 \%$ of BECs $>300$ cells/ $\mu \mathrm{L}$ ). To qualify as persistently high, patients with 3 measurements were not allowed to have any BEC $\leq 300$ cells $/ \mu \mathrm{L}$, patients with 4-7 measurements were allowed to have only 1 $\mathrm{BEC} \leq 300$ cells $/ \mu \mathrm{L}$, patients with $8-11$ measurements were allowed to have 2 BECs $\leq 300$ cells $/ \mu \mathrm{L}$, patients with $12-15$ measurements were allowed to have 3 BECs $\leq 300$ cells $/ \mu \mathrm{L}$, patients with 16-19 measurements were allowed to have 4 BECs $\leq 300$ cells $/ \mu \mathrm{L}$, and patients with $20-23$ measurements were allowed to have $5 \mathrm{BECs} \leq 300$ cells $/ \mu \mathrm{L}$. Blood eosinophil counts $\leq 300$ cells $/ \mu \mathrm{L}$ that were measured during antiinterleukin- 5 therapy or $\leq 4$ weeks after an OCS prescription $(0.2 \%$ of values) were not considered valid, as the counts may have been reduced by therapy.

\section{Baseline Asthma Disease Burden}

Characteristics of asthma examined during the baseline year included Global Initiative for Asthma (GINA) step of asthma management according to $2018^{28}$ and $2019^{29}$ definitions, medication use, severe asthma exacerbations, acute respiratory events, and symptom control metrics. A severe asthma exacerbation was defined according to American Thoracic Society/European Respiratory Society criteria ${ }^{30}$ as an asthma-related hospitalization or emergency department (ED) visit and/or a prescription for acute OCS. An acute respiratory event was defined as an asthma-related hospitalization or ED visit, a prescription for acute OCS, and/or a prescription for antibiotics in conjunction with an asthma-related primary care consultation. Baseline symptom control, measured in patients with an annual asthma review within 15 months of the baseline period, was scored from 0 to 3 based on Royal College of Physicians questions for asthma. ${ }^{31}$ Poor symptom control was characterized by the presence of any 3 of following symptoms: difficulty sleeping due to asthma, usual asthma symptoms during the day (cough, wheeze, chest tightness, or breathlessness), interference of asthma with usual activities, or $>2$ puffs of SABA prescribed per week on average over the baseline year. Uncontrolled asthma in patients treated at GINA step 4 or treatment at GINA step 5 irrespective of control status was categorized as difficult-to-treat asthma.

\section{Asthma Outcomes}

Asthma outcomes were evaluated during the 12 months after the index date and included severe asthma exacerbations, acute respiratory events, and measures of asthma control. Severe asthma exacerbations were based on data from CPRD and were defined as a hospitalization with asthma as the primary diagnosis, a respiratory-related ED visit, prescription for acute OCS, and/or an EMR recording of an acute exacerbation. An acute respiratory event was defined as a hospitalization with asthma as the primary diagnosis, 
a respiratory-related ED visit, a prescription for acute OCS, an EMR recording of an acute exacerbation, and/or prescription for antibiotics in conjunction with an asthma-related primary care consultation. Asthma control was assessed by 3 measures: risk domain asthma control (RDAC), overall asthma control, and full asthma control. Patients achieved RDAC if they had neither an acute respiratory event nor a respiratory-related outpatient visit during the outcome year. Overall asthma control required attainment of $\mathrm{RDAC}$ and that the patient was receiving an average daily dose of $\leq 200-\mu \mathrm{g}$ salbutamol $/ \leq 500-\mu \mathrm{g}$ terbutaline. ${ }^{32}$ Full asthma control was defined as the absence of frequent $(\geq 2)$ OCS course prescriptions, respiratory hospital admission, ED visit, or poor symptom control.

\section{Health Care Resource Utilization}

HCRU was measured for 12 months after the index date using data from CPRD and included physician office visits, outpatient visits, ED visits, and hospital admissions (all-cause, asthma as the primary diagnosis, asthma at any diagnostic position, and a respiratory condition as the primary diagnosis).

\section{Statistical Analysis}

Descriptive statistics were reported for all variables. Due to its log-normal distribution, geometric means and geometric standard deviations were calculated for BECs. To examine statistical significance of differences in distribution of characteristics among the endotypes, Pearson's chi-square tests of independent categories for categorical variables and the nonparametric Kruskal-Wallis equality-of-populations rank test for variables on a continuous or ordinal scale were performed. Relevant differences in crude distribution of characteristics between longitudinal eosinophil pattern groups were reported as the standardized mean difference (SMD) with the persistently high group as the reference. The SMD is not affected by the number of observations and provides information on the magnitude of differences and is, therefore, more informative than $P$ values for these types of analyses. ${ }^{33}$ An SMD $>10 \%$ indicates a relevant difference.

To study the association between eosinophil pattern and asthma control after adjustment for potential confounders, negative binomial regression analyses were performed with the number of severe exacerbations in the outcome year as the outcome variable. For these analyses, the EMR-based definition of severe exacerbation was used in the full population of patients (OPCRD+CPRD). Covariates tested in the model included number of BECs available, mean annual rate of
BEC measurements, sex, age, smoking habits, and presence of comorbidities. Covariates were considered relevant confounders if they changed the association coefficient by $\geq 5 \%$. Rate ratios and 95\% confidence intervals after adjustment for confounders are reported. Statistical analyses were performed using Stata MP/6 version 15.1 (StataCorp LLC, College Station, Texas, USA).

\section{Results}

A total of 148,021 patients were eligible for inclusion in the study population: 77,715 patients from OPCRD and 70,306 from CPRD (Figure 2). The mean age was $56.0 \pm$ 17.7 years, and $68.5 \%$ of patients were women. The median interval between asthma diagnosis and the index date was 15 years (interquartile range [IQR], 9-24 years).

\section{Blood Eosinophil Counts}

Patients had a median of 6 (IQR, 4-10) BEC measurements recorded during the study interval, with a median of 0.84 (IQR, 0.54-1.28) measurements per individual follow-up year. Persistently high BECs $(\geq 75 \%$ of counts $>300$ cells/ $\mu \mathrm{L}$ ) were detected in $13.6 \%$ of patients, intermittently high ( $\geq 1$ count and $<75 \%$ of counts $>300$ cells $/ \mu \mathrm{L}$ ) in $40.5 \%$ of patients, and never high in $45.9 \%$ of patients. The proportion of patients with no high eosinophil recording decreased with the number of available eosinophil measurements, resulting in a larger proportion of patients in the intermittently high group as the number of measurements increased from the minimum of 3 (Figure 3 ). The percentage of patients in the persistently high group varied only modestly for patients with 6 or more BEC measurements.

The persistently high group had a lower mean age and a greater proportion of male patients compared with the intermittently high and never high groups (SMD $>10 \%$ for all comparisons; Table 1). These patients also had a higher prevalence of nasal polyps and allergic rhinitis but a lower prevalence of anxiety/depression than the other 2 groups (Tables 1 and 2). Overall, the burden of comorbidities, as measured by the Charlson comorbidity index, was lower for patients categorized as persistently high vs intermittently high $(\mathrm{SMD}=12.7 \%)$.

\section{Asthma Severity During the Baseline Period}

GINA step of asthma management was not appreciably more advanced in patients in the persistently high group compared with the intermittently high group (Table 3). 


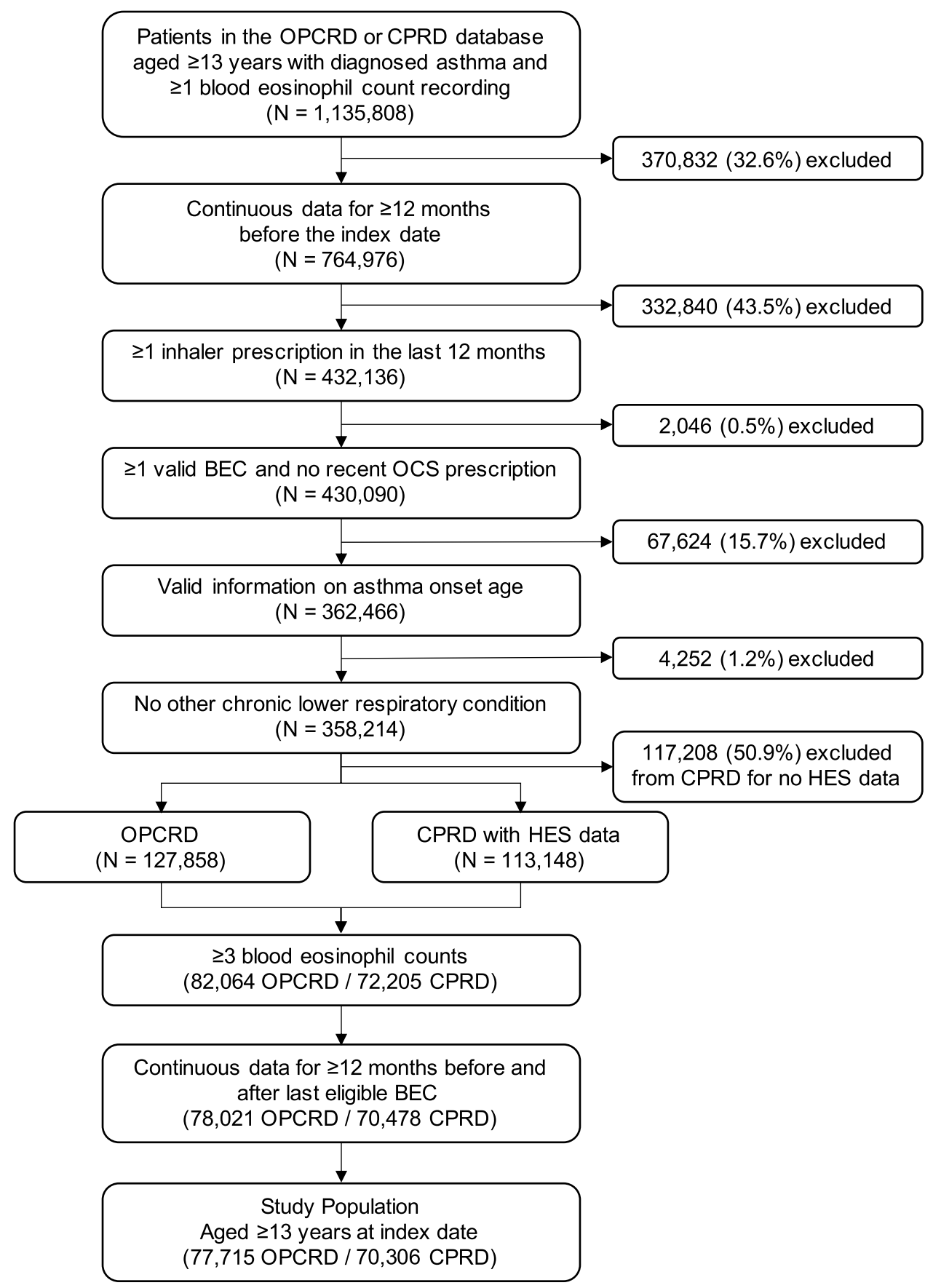

Figure 2 Patient selection criteria.

Abbreviations: BEC, blood eosinophil count; CPRD, Clinical Practice Research Datalink; HES, Hospital Episode Statistics; OCS, oral corticosteroid; OPCRD, Optimum Patient Care Research Database.

However, moderate to severe asthma (GINA step 3-5) was more common in the intermittently $(59.0 \%)$ or persistently high $(61.2 \%)$ groups than in the never high group $(54.0 \%)$. Consistent with the inclusion criteria, the majority of patients in all groups were receiving ICS. The proportion of patients not receiving ICS decreased from $19.9 \%$ in the never high group to $17.2 \%$ in the intermittently high group and $14.9 \%$ in the persistently high group. Less excessive SABA use ( $>300 \mu \mathrm{g}$ mean daily salbutamol equivalent) was observed in the never high group (30.0\%) vs the intermittently $(35.0 \%)$ or persistently high $(36.6 \%)$ groups. Maintenance OCS use was not meaningfully different between treatment groups, but the number of patients with a mean daily dose $>7.5 \mathrm{mg}$ was higher in the 


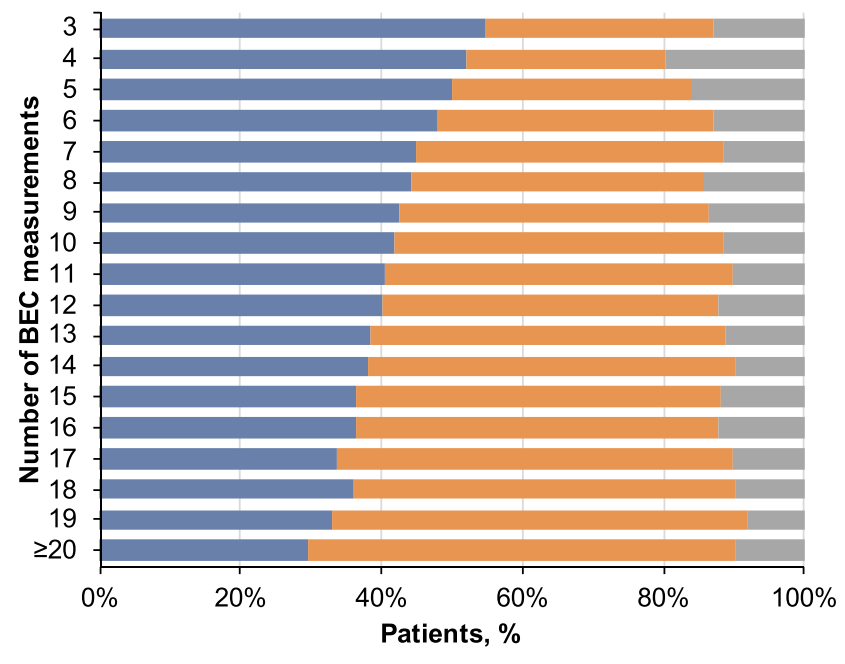

Never high Intermittently high $\quad$ Persistently high

Figure 3 Distribution of longitudinal eosinophil patterns by the number of blood eosinophil measurements available. The proportion of patients classified as persistently high, intermittently high, or never high are shown by total number of blood eosinophil count (BEC) measurements available.

intermittent group $(1.2 \%)$ than in the persistent $(0.6 \%)$ and never high groups $(0.7 \%)$.

\section{Asthma Control During the Outcome Year}

A greater percentage of patients with $\geq 1$ BEC $>300$ cells/ $\mu \mathrm{L}$ (persistently high, 26.0\%; intermittently high, $25.7 \%$ ) experienced $\geq 1$ severe asthma exacerbation during the outcome year compared with the never high group (21.7\%; Table 4). Other measures of asthma control were not appreciably different among blood eosinophil pattern groups. Full asthma control was achieved by $22.3 \%$, $24.3 \%$, and $23.6 \%$ of patients in the persistently high, intermittently high, and never high groups, respectively.

After adjustment for confounders, patients in the persistently high and intermittently high groups had similarly elevated severe exacerbation risk compared with the never high group (Table 5). A history of nasal polyps, older age, anxiety or depression, rate of BEC measurements per year, and overall number of measurements available were independent predictors of increased severe exacerbation risk ( $P<0.001$ for all comparisons). Smoking status significantly modified the association between blood eosinophil patterns and severe exacerbation risk $(P<0.001$; Figure 4). Patients who never smoked and had persistently high BECs had a $47 \%$ greater risk of severe exacerbations compared with never smokers in the never high group. The increase in the intermittently high group was $27 \%$ relative to the never high group. For ex-smokers, a similar increase in risk was found in the persistently high and intermittently high groups (32\% and 28\%, respectively). Current smokers had a diminished, but significant, increase in severe exacerbation risk associated with persistently or intermittently high BECs.

\section{Health Care Resource Utilization During the Outcome Year}

The mean number of all-cause general practitioner consultations was greater in the intermittently high group vs the never high or persistently high groups $(\mathrm{SMD}=15.1 \%)$; this trend was not observed for respiratory conditionrelated visits (Table 6). Hospital admissions due to asthma or a respiratory condition as the primary diagnosis were rare events and not meaningfully different among groups. Within the small population of patients with an asthmarelated hospital admission, those with persistently high BECs had a shorter mean length of stay ( $4.7 \pm 7.6$ days $)$ than the never high $(8.0 \pm 12.2$ days; $\mathrm{SMD}=32.8 \%)$ and intermittently high patients $(6.9 \pm 11.2$ days; $\mathrm{SMD}=$ $23.1 \%$ ). Similar results were found for inpatient admissions with a respiratory condition as the primary diagnosis.

\section{Discussion}

Results from this large observational cohort highlight the role of eosinophil elevations as a prognostic marker of asthma exacerbation risk. Among patients with at least 3 BEC measures, those with at least 1 elevated BEC (ie, $\mathrm{BEC}>300$ cells $/ \mu \mathrm{L}$ ), regardless of whether the elevation was persistent or intermittent, were at greater risk for severe asthma exacerbations compared with patients with no BECs $>300$ cells $/ \mu \mathrm{L}$. Moreover, risk was increased to a similar degree in patients with persistently or intermittently high BECs. These findings imply that a single high eosinophil measurement is sufficient to identify patients with elevated risk of severe asthma exacerbations.

In this data set, persistently high $\mathrm{BEC}$ was present in $13.6 \%$ of patients, whereas either persistently or intermittently high BEC was detected in $54.1 \%$ of the study population. These data are consistent with a prior longitudinal study of sequential sputum samples taken during routine clinic visits in which $29 \%$ of children with mild to moderate asthma had elevated eosinophil counts in all samples and 24\% had a mixture of sputum samples that were eosinophilic and noneosinophilic. $^{22}$ In previous studies where a single measurement was used to categorize eosinophil elevations, ${ }^{13,21}$ the 
Table I Patient Demographics and Baseline Characteristics

\begin{tabular}{|c|c|c|c|}
\hline Parameter & $\begin{array}{l}\text { Never High } \\
(N=67,980)\end{array}$ & $\begin{array}{l}\text { Intermittently High } \\
\qquad(N=59,894)\end{array}$ & $\begin{array}{l}\text { Persistently High } \\
(N=20,147)\end{array}$ \\
\hline Mean age, years $\pm S D^{a, b}$ & $56.2 \pm 17.2$ & $56.5 \pm 18.0$ & $53.9 \pm 18.6$ \\
\hline Male, n (\%) & $18,775(27.6)$ & 19,803 (33.1) & $8,070(40.1)$ \\
\hline \multicolumn{4}{|l|}{ Smoking status, n (\%) } \\
\hline$N$ & 64,973 & 57,547 & 19,288 \\
\hline Never smoker & $23,636(36.4)$ & $20,362(35.4)$ & $7572(39.3)$ \\
\hline Current smoker & $10,160(15.6)$ & $8423(14.6)$ & $2777(14.4)$ \\
\hline Ex-smoker & $31,177(48.0)$ & $28,762(50.0)$ & $8939(46.3)$ \\
\hline \multicolumn{4}{|l|}{ BMI, n (\%) } \\
\hline $\mathrm{N}$ & 64,500 & 57,065 & $|8,93|$ \\
\hline$<18.5 \mathrm{~kg} / \mathrm{m}^{2}$ & $1086(1.7)$ & $1150(1.9)$ & $45 I(2.4)$ \\
\hline$\geq 18.5$ to $<25 \mathrm{~kg} / \mathrm{m}^{2}$ & $16,798(26.0)$ & $14,884(26.1)$ & $5278(27.9)$ \\
\hline$\geq 25$ to $<30 \mathrm{~kg} / \mathrm{m}^{2}$ & $21,338(33.1)$ & $18,818(33.0)$ & $6356(33.6)$ \\
\hline$\geq 30 \mathrm{~kg} / \mathrm{m}^{2}$ & $25,278(39.2)$ & $22,258(39.0)$ & $6846(36.2)$ \\
\hline Mean number of $\mathrm{BECs} \pm \mathrm{SD}^{\mathrm{b}}$ & $7.7 \pm 7.6$ & $10.5 \pm 11.7$ & $7.7 \pm 7.3$ \\
\hline Median (IQR) & $6.0(4.0,9.0)$ & $7.0(5.0,12.0)$ & $5.0(4.0,9.0)$ \\
\hline Mean number of BECs per year $\pm S D^{b}$ & $1.0 \pm 0.9$ & $1.2 \pm 1.2$ & $1.0 \pm 0.9$ \\
\hline Geometric mean $\mathrm{BEC}$ at index date, cells $/ \mu \mathrm{L} \pm \mathrm{SD}^{\mathrm{a}, \mathrm{b}}$ & $125.9 \pm 2.0$ & $251.2 \pm 2.0$ & $501.2 \pm 1.6$ \\
\hline \multicolumn{4}{|l|}{ BEC category, $\mathrm{n}(\%)^{\mathrm{a}, \mathrm{b}}$} \\
\hline$<150$ cells $/ \mu \mathrm{L}$ & $36,122(53.1)$ & 9291 (15.5) & $281(1.4)$ \\
\hline I50-300 cells/ $/ \mu \mathrm{L}$ & $31,868(46.9)$ & $31,288(52.2)$ & $1631(8.1)$ \\
\hline$>300$ cells $/ \mu \mathrm{L}$ & NA & $19,315(32.2)$ & $18,235(90.5)$ \\
\hline \multicolumn{4}{|l|}{ Age of asthma onset, $n(\%)^{a}$} \\
\hline Childhood (<18 yrs) & $14,668(2 \mid .6)$ & $15,316(25.6)$ & $5674(28.2)$ \\
\hline Adult (I8-29 yrs) & $8288(12.2)$ & $759 \mid$ (I2.7) & $2619(13.0)$ \\
\hline Late-onset ( $\geq 30$ yrs) & $45,024(66.2)$ & $36,987(61.8)$ & I I,854 (58.8) \\
\hline History of nasal polyps, $n(\%)^{a, b}$ & $1255(1.8)$ & $3028(5.1)$ & $2167(10.8)$ \\
\hline \multicolumn{4}{|l|}{ Charlson comorbidity index, $\mathrm{n}(\%)^{\mathrm{b}}$} \\
\hline $\mathrm{N}$ & 66,188 & 58,444 & 19,651 \\
\hline $0-1$ & $46,335(70.0)$ & $38,131(65.2)$ & 13,913 (70.8) \\
\hline $2-3$ & $14,526(21.9)$ & 14,044 (24.0) & $4176(21.3)$ \\
\hline$\geq 4$ & $5327(8.0)$ & $6269(10.7)$ & $1562(7.9)$ \\
\hline Maintenance $O C S^{c}$ in baseline year, $n(\%)$ & $489(0.7)$ & $743(1.2)$ & $126(0.6)$ \\
\hline Ever used anti-interleukin-5 therapy, n (\%) & $<5$ & $<5$ & $<5$ \\
\hline $\begin{array}{l}\text { Severe exacerbations according to EMR during the baseline year, mean } \pm \\
\text { SD }\end{array}$ & $0.42 \pm 1.16$ & $0.57 \pm 1.44$ & $0.52 \pm 1.30$ \\
\hline \multicolumn{4}{|l|}{ Severe exacerbations ${ }^{\mathrm{d}}$ in baseline year, $\mathrm{n}(\%)^{\mathrm{a}}$} \\
\hline 0 & $53,172(78.2)$ & $44,165(73.7)$ & 14,857 (73.7) \\
\hline 1 & $9185(13.5)$ & $8955(15.0)$ & $3124(15.5)$ \\
\hline 2 & $2929(4.3)$ & $3187(5.3)$ & $1028(5.1)$ \\
\hline 3 & $1114(1.6)$ & $1288(2.2)$ & $499(2.5)$ \\
\hline$\geq 4$ & $1580(2.3)$ & $2299(3.8)$ & $639(3.2)$ \\
\hline
\end{tabular}

Notes: $\mathrm{P}<0.00 \mathrm{I}$ for tests of independence/equality of populations for all categories except use of anti-interleukin- 5 therapy. ${ }^{2}$ Standardized mean difference (SMD) $>10 \%$ for comparison of never high and persistently high. ${ }^{\mathrm{b}} \mathrm{SMD}>10 \%$ for comparison of intermittently high and persistently high. "Maintenance OCS use was determined using an algorithm that took into account the dosing instructions, daily dosage, strength of prescription, number of prescriptions, and concurrent diagnostic codes that would indicate acute rather than maintenance use. ${ }^{\mathrm{d} A}$ severe exacerbation in the baseline year was defined as an asthma-related hospitalization or emergency department visit and/or a prescription for acute OCS. Abbreviations: BEC, blood eosinophil count; BMI, body mass index; EMR, electronic medical record; IQR, interquartile range; NA, not applicable; OCS, oral corticosteroid; SD, standard deviation. 
Table 2 Distribution of Comorbidities by Longitudinal Eosinophil Pattern

\begin{tabular}{|c|c|c|c|}
\hline Variable & Never High $(\mathrm{N}=67,980)$ & Intermittently High $(\mathrm{N}=\mathbf{5 9 , 8 9 4 )}$ & Persistently High $(N=20,147)$ \\
\hline \multicolumn{4}{|l|}{ Eczema $^{a}$} \\
\hline No, n (\%) & $49,854(73.3)$ & $41,129(68.7)$ & 13,647 (67.7) \\
\hline Yes, inactive, n (\%) & 12,738 (18.7) & 12,392 (20.7) & $3880(19.3)$ \\
\hline Yes, active, n (\%) & $5388(7.9)$ & $6373(10.6)$ & $2620(13.0)$ \\
\hline \multicolumn{4}{|l|}{ Allergic rhinitis ${ }^{\mathrm{a}, \mathrm{b}}$} \\
\hline No, n (\%) & $47,167(69.4)$ & $38,229(63.8)$ & $|2,0| \mid(59.6)$ \\
\hline Yes, inactive, n (\%) & $12,378(18.2)$ & 12,273 (20.5) & $4197(20.8)$ \\
\hline Yes, active, n (\%) & $8435(12.4)$ & $9392(15.7)$ & $3939(19.6)$ \\
\hline Urticaria ever, n (\%) & $5659(8.3)$ & $5944(9.9)$ & $1969(9.8)$ \\
\hline Food allergy ever, $\mathrm{n}(\%)$ & $1345(2.0)$ & $152 \mid(2.5)$ & $679(3.4)$ \\
\hline Anaphylaxis ever, n (\%) & $364(0.5)$ & $427(0.7)$ & $153(0.8)$ \\
\hline Aspirin sensitivity ever, n (\%) & $877(1.3)$ & $925(1.5)$ & $229(1.1)$ \\
\hline \multicolumn{4}{|l|}{ Chronic rhinosinusitis $^{\mathrm{a}}$} \\
\hline No, n (\%) & $60,184(88.5)$ & $51,596(86.1)$ & $16,990(84.3)$ \\
\hline Yes, without nasal polyps, n (\%) & $7375(10.8)$ & $7111(11.9)$ & $2234(11.1)$ \\
\hline Yes, with nasal polyps, n (\%) & $421(0.6)$ & $1187(2.0)$ & $923(4.6)$ \\
\hline COPD ever, n (\%) & $5576(8.2)$ & $5559(9.3)$ & $1563(7.8)$ \\
\hline GERD ever, $\mathrm{n}(\%)$ & $|4,23|(20.9)$ & $13,020(21.7)$ & $3587(17.8)$ \\
\hline Diabetes mellitus ever, n (\%) & $8181(12.0)$ & $9390(15.7)$ & $2769(13.7)$ \\
\hline Osteoporosis ever, n (\%) & $3365(4.9)$ & $3155(5.3)$ & $804(4.0)$ \\
\hline Hypertension ever, n (\%) & $23,072(33.9)$ & $21,395(35.7)$ & $6311(31.3)$ \\
\hline Cardiovascular disease ever, $\mathrm{n}(\%)^{\mathrm{b}}$ & $13,312(19.6)$ & 13,274 (22.2) & $3637(18.1)$ \\
\hline Ischemic heart disease ever, $\mathrm{n}(\%)$ & $5910(8.7)$ & $6393(10.7)$ & $1846(9.2)$ \\
\hline Heart failure ever, n (\%) & $1324(1.9)$ & $1539(2.6)$ & $383(1.9)$ \\
\hline Myocardial infarction ever, n (\%) & $2085(3.1)$ & $2624(4.4)$ & $847(4.2)$ \\
\hline CKD, stage 3-5 ever, n (\%) & $5391(7.9)$ & $6058(10.1)$ & $1704(8.5)$ \\
\hline Anxiety/depression ever, $\mathrm{n}(\%)^{\mathrm{a}, \mathrm{b}}$ & $33,671(49.5)$ & $29,179(48.7)$ & $844 I(4 I .9)$ \\
\hline Apnea ever, n (\%) & $1069(1.6)$ & $1136(1.9)$ & $334(1.7)$ \\
\hline Pneumonia diagnosis ever, n (\%) & $3572(5.3)$ & $3766(6.3)$ & $1135(5.6)$ \\
\hline
\end{tabular}

Notes: $\mathrm{P}<0.00 \mathrm{I}$ for tests of independence for all categories. ${ }^{\mathrm{a} S}$ Standardized mean difference (SMD) $>10 \%$ for comparison of never high and persistently high. ${ }^{\mathrm{b}} \mathrm{SMD}>10 \%$ for comparison of intermittently high and persistently high.

Abbreviations: CKD, chronic kidney disease; COPD, chronic obstructive pulmonary disease; GERD, gastroesophageal reflux disease.

proportion of patients with high BEC $(\geq 300$ cells $/ \mu \mathrm{L})$ was lower (33\% to $43 \%)$, likely reflecting the decreased detection of BEC elevations when only 1 measurement was used versus the minimum of 3 measurements required in the current study. The comparable increase in the risk of severe exacerbations in the intermittently high and persistently high BEC groups observed in our study underscores the need to identify patients in both groups.
Despite the similar risk of severe exacerbations in the persistently high and intermittently high BEC groups, there were notable areas of divergence. Compared with the intermittently high group, patients in the persistently high group had a greater prevalence of nasal polyps $(5.1 \%$ vs $10.8 \%$ ), a condition known to be associated with eosinophil elevations ${ }^{34}$ and an independent predictor of severe asthma exacerbation risk in our analysis. For patients who 
Table 3 Distribution of Asthma Therapy in the Baseline Year by Longitudinal Eosinophil Pattern

\begin{tabular}{|c|c|c|c|}
\hline Variable & Never High $(\mathbf{N}=67,980)$ & $\begin{array}{l}\text { Intermittently High } \\
\qquad(\mathbf{N}=\mathbf{5 9 , 8 9 4 )}\end{array}$ & $\begin{array}{l}\text { Persistently High } \\
\qquad(N=20,147)\end{array}$ \\
\hline \multicolumn{4}{|l|}{ GINA step (2019), n (\%) ${ }^{\mathrm{a}, \dagger}$} \\
\hline $\mathrm{I}$ & $12,884(19.0)$ & $9742(16.3)$ & $2836(14.1)$ \\
\hline 2 & I8,377 (27.0) & $14,805(24.7)$ & $4986(24.7)$ \\
\hline 3 & II,657 (I7.I) & $10,173(17.0)$ & $3500(17.4)$ \\
\hline 4 & $14,552(21.4)$ & $13,876(23.2)$ & $4978(24.7)$ \\
\hline 5 & $10,510(15.5)$ & $11,298(18.9)$ & $3847(19.1)$ \\
\hline \multicolumn{4}{|l|}{ GINA step (2018), n (\%) ${ }^{a, \dagger}$} \\
\hline 1 & $12,884(19.0)$ & $9742(16.3)$ & $2836(14.1)$ \\
\hline 2 & I8,377 (27.0) & $14,805(24.7)$ & $4986(24.7)$ \\
\hline 3 & $12,663(18.6)$ & $11,123(18.6)$ & $3845(19.1)$ \\
\hline 4 & $23,778(35.0)$ & $23,766(39.7)$ & $8397(41.7)$ \\
\hline 5 & $278(0.4)$ & $458(0.8)$ & $83(0.4)$ \\
\hline \multicolumn{4}{|l|}{ Last ICS management step, $\mathrm{n}(\%)^{\mathrm{a}, \dagger}$} \\
\hline No ICS & 13,529 (19.9) & $10,279(17.2)$ & $2995(14.9)$ \\
\hline Low-dose ICS monotherapy & $19,652(28.9)$ & I5,904 (26.6) & $5318(26.4)$ \\
\hline Low-dose ICS/LABA & $5495(8.1)$ & $5273(8.8)$ & $1893(9.4)$ \\
\hline Medium-dose ICS monotherapy & $6370(9.4)$ & $5326(8.9)$ & $17 \mid 4(8.5)$ \\
\hline Medium-dose ICS/LABA & I5,895 (23.4) & I5,443 (25.8) & $5512(27.4)$ \\
\hline High-dose ICS monotherapy & $503(0.7)$ & $565(0.9)$ & $249(1.2)$ \\
\hline High-dose ICS/LABA & $6526(9.6)$ & $7087(11.8)$ & $2460(12.2)$ \\
\hline Triple therapy inhaler & $10(0.0)$ & $17(0.0)$ & $6(0.0)$ \\
\hline \multicolumn{4}{|l|}{ ICS, mean daily dose FP equivalent $(\mu \mathrm{g})$} \\
\hline Mean $\pm \mathrm{SD}^{\dagger}$ & $381.8 \pm 639.1$ & $406.1 \pm 649.7$ & $415.0 \pm 667.1$ \\
\hline Median (IQR) & $164.0(33.0,439.0)$ & $193.0(55.0,484.0)$ & $197.0(55.0,477.0)$ \\
\hline \multicolumn{4}{|l|}{ ICS dose category, n (\%) ${ }^{\mathrm{a}, \dagger}$} \\
\hline 0 & $13,532(19.9)$ & $10,284(17.2)$ & $2995(14.9)$ \\
\hline 1 & $12,552(18.5)$ & $10,62 \mid(17.7)$ & $3679(18.3)$ \\
\hline 2 & $10,843(16.0)$ & $9696(16.2)$ & $3460(17.2)$ \\
\hline 3 & $16,390(24.1)$ & I5,263 (25.5) & $5352(26.6)$ \\
\hline 4 & $14,663(21.6)$ & $14,030(23.4)$ & $466 I(23.1)$ \\
\hline \multicolumn{4}{|l|}{ ICS possession ratio during the baseline year (\%) } \\
\hline $\mathrm{N}$ (\% non-missing) & $54,448(80.1)$ & $49,610(82.8)$ & $17,152(85.1)$ \\
\hline Mean $\pm \mathrm{SD}^{\dagger}$ & $74.4 \pm 54.4$ & $73.5 \pm 53.4$ & $71.0 \pm 50.8$ \\
\hline Median (IQR) & $66.0(33.0,100.0)$ & $64.0(34.0,99.0)$ & $62.0(34.0,96.0)$ \\
\hline \multicolumn{4}{|l|}{ ICS possession ratio category, $\mathrm{n}(\%)^{\dagger}$} \\
\hline$<50$ & $20,591(37.8)$ & $18,829(38.0)$ & $6711(39.1)$ \\
\hline $50-69$ & $8312(15.3)$ & $8015(16.2)$ & $2874(16.8)$ \\
\hline 70-79 & $3529(6.5)$ & $3263(6.6)$ & $1200(7.0)$ \\
\hline$\geq 80$ & $22,016(40.4)$ & $19,503(39.3)$ & $6367(37.1)$ \\
\hline \multicolumn{4}{|l|}{ Number of ICS inhalers for 30 days dispensed in baseline year } \\
\hline Mean $\pm \mathrm{SD}^{\dagger}$ & $7.3 \pm 6.9$ & $7.4 \pm 6.8$ & $7.4 \pm 6.4$ \\
\hline Median (IQR) & $6.0(2.0,11.0)$ & $6.0(2.0,11.0)$ & $6.0(3.0,11.0)$ \\
\hline \multicolumn{4}{|l|}{ ICS inhaler category, n (\%) ${ }^{\dagger}$} \\
\hline 0 & II,353 (16.7) & $8832(14.7)$ & $2560(12.7)$ \\
\hline $1-3$ & 12,933 (19.0) & II,I55 (18.6) & $3713(18.4)$ \\
\hline $4-6$ & ||$, 68 \mid(\mid 7.2)$ & $11,116(18.6)$ & $4066(20.2)$ \\
\hline
\end{tabular}

(Continued) 
Table 3 (Continued).

\begin{tabular}{|c|c|c|c|}
\hline Variable & Never High $(\mathbf{N}=67,980)$ & $\begin{array}{l}\text { Intermittently High } \\
\qquad(N=59,894)\end{array}$ & $\begin{array}{l}\text { Persistently High } \\
(N=20,147)\end{array}$ \\
\hline $7-9$ & $9347(13.7)$ & $8724(14.6)$ & $3237(16.1)$ \\
\hline$>9$ & $22,666(33.3)$ & $20,067(33.5)$ & $6571(32.6)$ \\
\hline \multicolumn{4}{|l|}{ SABA, mean daily dose salbutamol equivalent $(\mu \mathrm{g})^{\mathrm{a}}$} \\
\hline $\mathrm{N}$ (\% non-missing) & $60,836(89.5)$ & $54,468(90.9)$ & $|8,38|(9 \mid .2)$ \\
\hline Mean $\pm \mathrm{SD}^{\dagger}$ & $270.0 \pm 427.5$ & $318.4 \pm 534.8$ & $321.1 \pm 485.3$ \\
\hline Median (IQR) & $164.0(55.0,329.0)$ & $164.0(55.0,438.0)$ & $164.0(55.0,438.0)$ \\
\hline \multicolumn{4}{|l|}{ SABA dose category, $\mathrm{n}(\%)^{\mathrm{a}, \dagger}$} \\
\hline 0 & $10,083(16.6)$ & $8259(15.2)$ & $2606(14.2)$ \\
\hline $1-100$ & $10,110(16.6)$ & $7947(14.6)$ & $2615(14.2)$ \\
\hline $10 \mathrm{I}-200$ & $14,205(23.3)$ & $11,962(22.0)$ & $4006(21.8)$ \\
\hline $20 \mathrm{I}-300$ & $8193(13.5)$ & $7221(13.3)$ & $2428(13.2)$ \\
\hline $30 I-400$ & $550 I(9.0)$ & $5188(9.5)$ & $1885(10.3)$ \\
\hline$>400$ & I2,744 (20.9) & $|3,89|(25.5)$ & $484 \mid(26.3)$ \\
\hline OCS, mean daily dose $\pm \mathrm{SD}(\mathrm{mg})^{\dagger}$ & $0.3 \pm 1.4$ & $0.5 \pm 1.9$ & $0.4 \pm 1.5$ \\
\hline \multicolumn{4}{|l|}{ OCS dose category, n (\%) ${ }^{\dagger}$} \\
\hline 0 & $53,225(78.3)$ & $44,127(73.7)$ & $14,857(73.7)$ \\
\hline$>0$ to $<2.5$ & $12,700(18.7)$ & $12,855(2 \mid .5)$ & $4563(22.6)$ \\
\hline$\geq 2.5$ to $<5$ & $1206(1.8)$ & $1578(2.6)$ & $432(2.1)$ \\
\hline$\geq 5$ to $<7.5$ & $37 \mid(0.5)$ & $620(1.0)$ & $167(0.8)$ \\
\hline$\geq 7.5$ & $478(0.7)$ & $714(1.2)$ & $128(0.6)$ \\
\hline SAMA $\geq$ I prescription, $\mathrm{n}(\%)^{\dagger}$ & $1450(2.1)$ & $1425(2.4)$ & $405(2.0)$ \\
\hline LAMA $\geq$ I prescription, $\mathrm{n}(\%)^{\dagger}$ & $3886(5.7)$ & $4 \mid 48(6.9)$ & IIIS (5.5) \\
\hline LABA $\geq$ I prescription, $n(\%)^{*}$ & $3243(4.8)$ & $2936(4.9)$ & $899(4.5)$ \\
\hline Theophylline $\geq$ I prescription, $\mathrm{n}(\%)^{\dagger}$ & $732(1.1)$ & $1039(1.7)$ & $391(1.9)$ \\
\hline 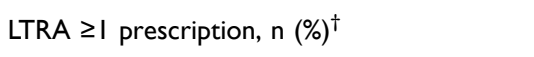 & $4570(6.7)$ & $4680(7.8)$ & $1836(9.1)$ \\
\hline Chromones $\geq$ I prescription, $\mathrm{n}(\%)$ & $35(0.1)$ & $34(0.1)$ & $16(0.1)$ \\
\hline Biologics $\geq$ I prescription, $\mathrm{n}(\%)$ & $<5$ & $<5$ & $<5$ \\
\hline Anti-lgE therapy ever $\geq$ I prescription, $n(\%)$ & $<5$ & $<5$ & $<5$ \\
\hline Anti-IL5 therapy ever $\geq$ I prescription, $n$ (\%)* & $<5$ & $<5$ & $<5$ \\
\hline Anti-IL4 therapy ever $\geq$ I prescription, $n(\%)$ & $<5$ & $<5$ & $<5$ \\
\hline
\end{tabular}

Notes: ${ }^{*} \mathrm{P}<0.05 ;{ }^{\dagger} \mathrm{P} \leq 0.001$ for tests of independence/equality of populations. ${ }^{\mathrm{a}}$ Standardized mean difference $>10 \%$ for comparison of never high and persistently high. Abbreviations: FP, fluticasone propionate; GINA, Global Initiative for Asthma; ICS, inhaled corticosteroid; IgE, immunoglobulin E; IL, interleukin; IQR, interquartile range; LABA, long-acting $\beta$-agonist; LAMA, long-acting muscarinic receptor antagonist; LTRA, leukotriene receptor antagonist; OCS, oral corticosteroid; SABA, short-acting $\beta 2$ agonist; SAMA, short-acting muscarinic receptor antagonist; SD, standard deviation.

never smoked, persistently high BEC was associated with a significantly greater risk of severe exacerbations compared with the intermittently high group. Risk of severe exacerbations was also greater in the persistently high and intermittently high groups relative to the never high group in current and former smokers, although the magnitude of risk increase was similar in the persistently high and intermittently high groups. In a prior analysis of CPRD data, an association was detected between a high BEC recorded within 1 year before hospital admission for asthma and increased risk of rehospitalization during the subsequent year in nonsmokers but not in current smokers. ${ }^{19}$ These data suggest that smoking may modify the relationship between BEC elevations and exacerbation 
Table 4 Asthma Control During the Outcome Year by Longitudinal Eosinophil Pattern

\begin{tabular}{|c|c|c|c|}
\hline Parameter & Never High $(\mathrm{N}=32,894)$ & $\begin{array}{l}\text { Intermittently High } \\
\qquad(\mathbf{N}=\mathbf{2 7 , 9 6 6 )}\end{array}$ & $\begin{array}{l}\text { Persistently High } \\
\qquad(N=9446)\end{array}$ \\
\hline $\begin{array}{l}\text { Severe asthma exacerbations }{ }^{\mathrm{a}} \text { mean } \pm \\
\text { SD }\end{array}$ & $0.41 \pm 1.15$ & $0.56 \pm 1.47$ & $0.53 \pm 1.29$ \\
\hline \multicolumn{4}{|l|}{$\begin{array}{l}\text { Severe asthma exacerbation category, } \\
n(\%)^{b}\end{array}$} \\
\hline None, n (\%) & $25,744(78.3)$ & $20,792(74.3)$ & $6989(74.0)$ \\
\hline I, n (\%) & $447 \mid(13.6)$ & $4079(14.6)$ & $1418(15.0)$ \\
\hline $2, \mathrm{n}(\%)$ & $1390(4.2)$ & $1429(5.1)$ & $498(5.3)$ \\
\hline $3, n(\%)$ & $546(1.7)$ & $624(2.2)$ & $228(2.4)$ \\
\hline$\geq 4, \mathrm{n}(\%)$ & $743(2.3)$ & $1042(3.7)$ & $313(3.3)$ \\
\hline $\begin{array}{l}\text { Acute lower respiratory events, mean } \pm \\
\text { SD }\end{array}$ & $0.74 \pm 1.52$ & $0.92 \pm 1.83$ & $0.83 \pm 1.58$ \\
\hline \multicolumn{4}{|l|}{$\begin{array}{l}\text { Acute lower respiratory event category, } \\
\text { n (\%) }\end{array}$} \\
\hline None, n (\%) & $20,767(63.1)$ & $16,787(60.0)$ & $5688(60.2)$ \\
\hline I, n (\%) & $7096(21.6)$ & $5947(21.3)$ & $2084(22.1)$ \\
\hline $2, \mathrm{n}(\%)$ & $2531(7.7)$ & $2369(8.5)$ & $817(8.6)$ \\
\hline $3, \mathrm{n}(\%)$ & $1059(3.2)$ & $|04|(3.7)$ & $354(3.7)$ \\
\hline$\geq 4, \mathrm{n}(\%)$ & $|44|(4.4)$ & $1822(6.5)$ & $503(5.3)$ \\
\hline Risk Domain Asthma Control, $\mathrm{n}(\%)^{\mathrm{c}}$ & $20,331(6 \mid .8)$ & $16,396(58.6)$ & $5534(58.6)$ \\
\hline Overall asthma control, $\mathrm{n}(\%)^{\mathrm{d}}$ & 3809 ( 11.6$)$ & $2774(9.9)$ & $910(9.6)$ \\
\hline Full asthma control, $\mathrm{n}(\%)^{\mathrm{e}}$ & $7776(23.6)$ & $6782(24.3)$ & $2107(22.3)$ \\
\hline
\end{tabular}

Notes: $\mathrm{P}<0.00 \mathrm{I}$ for tests of independence/equality of populations for all categories. ${ }^{\mathrm{a}} \mathrm{A}$ severe asthma exacerbation during the outcome year was defined as a hospitalization with asthma as the primary diagnosis, a respiratory-related emergency department visit, prescription for acute oral corticosteroids, and/or an acute exacerbation documented in the electronic medical record. 'btandardized mean difference $>10 \%$ for comparison of never high and persistently high. ${ }^{\mathrm{c}} \mathrm{Defined}$ as the absence of both an acute respiratory event and a respiratory-related outpatient visit. ${ }^{\mathrm{d} D e f i n e d ~ a s ~ a t t a i n m e n t ~ o f ~ R i s k ~ D o m a i n ~ A s t h m a ~ C o n t r o l ~ a n d ~ a n ~ a v e r a g e ~ d a i l y ~ d o s e ~ o f ~} \leq 200-\mu \mathrm{g}$ salbutamol/ $\leq 500-\mu \mathrm{g}$ terbutaline. ${ }^{\mathrm{e}}$ Defined as the absence of frequent $(\geq 2)$ oral corticosteroid course prescriptions, respiratory hospital admission, emergency department visit, or poor symptom control.

Abbreviation: SD, standard deviation.

Table 5 Association Between Eosinophil Pattern and the Rate of Exacerbations During the Outcome Year

\begin{tabular}{|c|c|c|c|}
\hline Variable & Category & Rate Ratio $(95 \% \mathrm{Cl})$ & $P$ value \\
\hline Persistence of BEC elevation & $\begin{array}{l}\text { No high } \mathrm{BEC} \\
\text { Persistently high BEC } \\
\text { Intermittently high BEC }\end{array}$ & $\begin{array}{c}\text { Reference } \\
1.28(1.24-1.33) \\
1.24(1.21-1.27)\end{array}$ & $\begin{array}{l}<0.001 \\
<0.001\end{array}$ \\
\hline $\begin{array}{l}\text { Confounders } \\
\text { Nasal polyps }\end{array}$ & $\begin{array}{l}\text { No } \\
\text { Yes }\end{array}$ & $\begin{array}{c}\text { Reference } \\
1.36(1.33,1.39)\end{array}$ & $<0.001$ \\
\hline Age per 10 years & & $1.28(1.23-1.33)$ & $<0.001$ \\
\hline $\mathrm{Age}^{2}$ per 10 years & & $0.99(0.99-0.99)$ & $<0.001$ \\
\hline Anxiety/depression & $\begin{array}{l}\text { No } \\
\text { Yes }\end{array}$ & $\begin{array}{c}\text { Reference } \\
1.36(1.33-1.39)\end{array}$ & $<0.001$ \\
\hline Rate of $\mathrm{BEC}$ measurements per year & & $1.23(1.21-1.25)$ & $<0.001$ \\
\hline Number of BEC measurements & & $1.01(1.00-1.01)$ & $<0.001$ \\
\hline
\end{tabular}

Note: Negative binomial regression analysis was performed with the number of exacerbations in the outcome year as the outcome variable and number of blood eosinophil counts available, mean annual rate of blood eosinophil count measurements, sex, age, smoking habits, and presence of comorbidities as covariates.

Abbreviations: $\mathrm{BEC}$, blood eosinophil count; $\mathrm{Cl}$, confidence interval. 


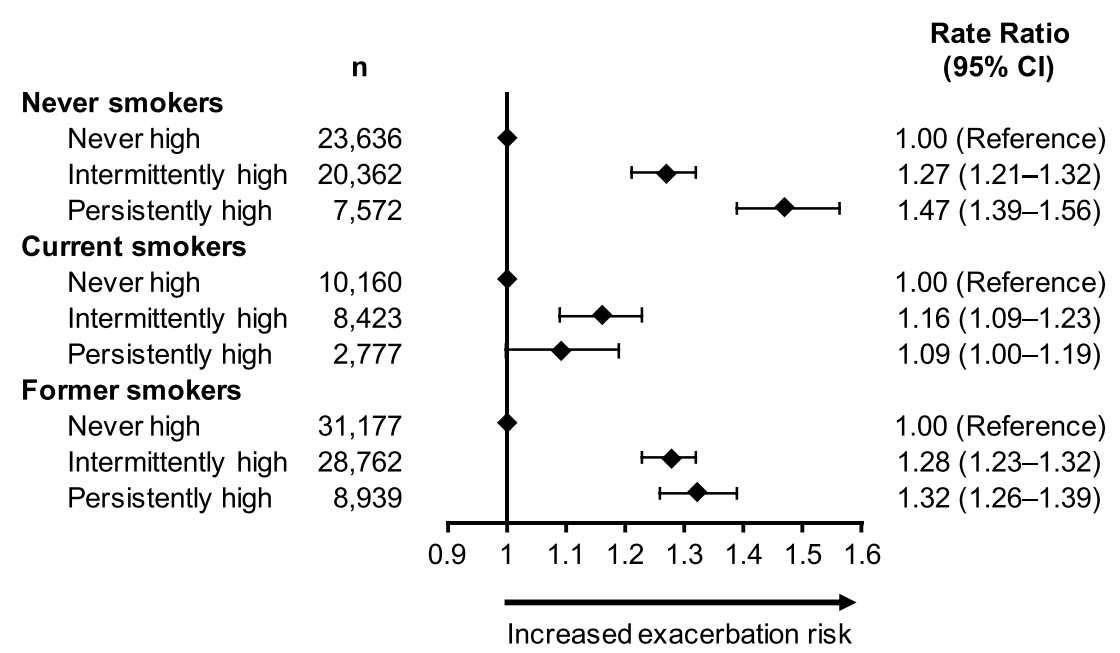

Figure 4 Association between longitudinal eosinophil patterns and exacerbations in the outcome year by smoking status. Abbreviation: $\mathrm{Cl}$, confidence interval.

risk. It is interesting to note that the proportion of patients who were current or former smokers in this study is similar between CPRD and OPCRD but greater than in previous UK studies, ${ }^{19,21}$ which may reflect the requirement for having at least $3 \mathrm{BEC}$ measurements. Patients with asthma who were current or former smokers may have more check-up visits and, thus, more blood eosinophil measurements performed. Further research is

Table 6 Health Care Resource Utilization During the Outcome Year by Longitudinal Eosinophil Pattern (Univariable Analysis)

\begin{tabular}{|c|c|c|c|}
\hline Parameter & Never High $(\mathbf{N}=32,894)$ & $\begin{array}{l}\text { Intermittently High } \\
(\mathbf{N}=\mathbf{2 7}, 966)\end{array}$ & $\begin{array}{l}\text { Persistently High } \\
(\mathrm{N}=9446)\end{array}$ \\
\hline All-cause GP consultations ${ }^{\mathrm{b}}$ & $12.54 \pm 9.56$ & $13.17 \pm 10.39$ & $11.71 \pm 8.86$ \\
\hline Respiratory-related GP consultations & $4.59 \pm 4.95$ & $4.73 \pm 5.10$ & $4.70 \pm 5.01$ \\
\hline All-cause outpatient visits & $3.76 \pm 6.01$ & $4.16 \pm 7.05$ & $3.51 \pm 6.05$ \\
\hline Respiratory outpatient visits & $0.10 \pm 0.71$ & $0.13 \pm 0.91$ & $0.13 \pm 0.89$ \\
\hline $\begin{array}{l}\text { All-cause emergency department visits } \\
\text { Patients with } \geq 4 \text { visits, } n \text { (\%) }\end{array}$ & $\begin{array}{l}0.45 \pm 1.48 \\
589(1.8)\end{array}$ & $\begin{array}{l}0.48 \pm 1.32 \\
608(2.2)\end{array}$ & $\begin{array}{l}0.42 \pm 1.06 \\
163(1.7)\end{array}$ \\
\hline Respiratory emergency department visits & $0.04 \pm 0.51$ & $0.05 \pm 0.32$ & $0.04 \pm 0.27$ \\
\hline Hospital admissions with asthma as the primary diagnosis & $0.01 \pm 0.19$ & $0.02 \pm 0.23$ & $0.01 \pm 0.20$ \\
\hline $\begin{array}{l}\text { Hospital admissions with a respiratory condition as the primary } \\
\text { diagnosis }\end{array}$ & $0.03 \pm 0.29$ & $0.05 \pm 0.35$ & $0.04 \pm 0.28$ \\
\hline $\begin{array}{l}\text { Patients with } \geq 1 \text { overnight hospitalization with asthma as the } \\
\text { primary diagnosis, } n\end{array}$ & 170 & 233 & 80 \\
\hline Length of stay ${ }^{\mathrm{a}, \mathrm{b}}$ & $8.0 \pm 12.2$ & $6.9 \pm 11.2$ & $4.7 \pm 7.6$ \\
\hline $\begin{array}{l}\text { Patients with } \geq 1 \text { overnight stay with a respiratory condition as } \\
\text { the primary diagnosis, } \mathrm{n}\end{array}$ & 1085 & 1339 & 391 \\
\hline Length of stay ${ }^{\mathrm{a}, \mathrm{b}}$ & $8.8 \pm 14.7$ & $9.5 \pm 16.0$ & $6.5 \pm 10.2$ \\
\hline
\end{tabular}

Notes: Data are means \pm standard deviations unless otherwise specified. $P<0.001$ for tests of independence/equality of populations for all categories except respiratory-

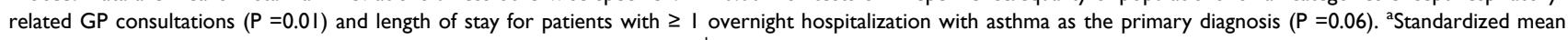
difference (SMD) $>10 \%$ for comparison of never high and persistently high. ${ }^{b} \mathrm{SMD}>10 \%$ for comparison of intermittently high and persistently high.

Abbreviation: GP, general practitioner. 
needed to understand the interactions between smoking, BEC elevations, and exacerbation risk.

Unlike exacerbation rates, no appreciable differences in other measures of asthma control were observed among blood eosinophil pattern groups. Notably, less than onequarter of patients across eosinophil groups achieved full asthma control during the outcome year. Differences in asthma treatment during the baseline year were minimal. Interestingly, $22 \%$ to $26 \%$ of patients were prescribed OCS, a small percent at moderate or high doses (mean daily dose $>5 \mathrm{mg}$ ), despite the associated risk for acute and chronic adverse events. ${ }^{6,35}$ These data add to the large body of literature indicating that a considerable proportion of patients in clinical practice have suboptimal asthma symptom control, many of whom would benefit from referral to a specialist for evaluation and management. ${ }^{36,37}$

In general, HCRU did not appreciably differ among patients in the 3 eosinophil elevation pattern groups. For patients with an asthma-related hospitalization, the length of stay was shorter for patients with persistent BEC elevations, particularly in comparison with patients in the never high group. This observation suggests that persistently high BECs may represent a distinct subset of patients within the eosinophilic endotype in whom eosinophilia dominates the etiology and, hence, respond rapidly to currently available eosinophil-targeted therapies. It should be noted, however, that the persistently high group had a lower comorbidity burden compared with the intermittently high group, which has been shown to affect asthmarelated hospital length of stay. ${ }^{38}$ Evaluation of treatment response in patients with differing eosinophil elevation patterns is warranted to better understand this patient subgroup.

Identifying a patient's asthma endotype has significant relevance to clinical practice. As the accumulated evidence suggests, eosinophil elevations indicate increased risk for asthma exacerbations and adverse outcomes, ${ }^{13-19}$ thus distinguishing a patient population in need of further monitoring and intervention. Patients with eosinophil elevations may also be candidates for biologic therapies targeting interleukin 5 or the interleukin-5 receptor. In clinical practice, however, measurement of BECs has not been incorporated as a universal facet of asthma management. Indeed, a prior analysis of data from OPCRD and CPRD found that only $52 \%$ of patients with asthma had BECs recorded in the EMR. ${ }^{15}$ Regular assessment of asthma endotype, including measurement of biomarker concentrations, is needed to improve implementation of individualized, targeted asthma management.

A major strength of this study was that it utilized a large data set in a first-of-its-kind analysis of longitudinal, repeated blood eosinophil measurements, which allowed for evaluation of the heretofore unexamined relationship between eosinophil elevation patterns and exacerbations. There are several limitations that affect the interpretation of these analyses. Full blood count measurements are not routinely performed (every 1 to 2 years) and are generally requested for a specific medical reason; therefore, ascertainment bias in the types of patients for whom BEC data were available cannot be excluded, and the study population may not be fully representative of the broader population of patients with asthma. In the OPCRD data set, for example, $43 \%$ of patients with a diagnostic code for asthma were not eligible for inclusion in the analysis due to lack of a BEC measurement. Comparable statistics were not available for the CPRD data set. Both the OPCRD and CPRD data sets comprise information collected for clinical and routine use rather than specifically for research purposes. Although extensive quality control and validity checks are conducted on the practice level, the validity and completeness of individual patient records may be limited. Among the possible influences on BECs, we cannot exclude the potential effect of ICS, which was used by the majority of patients in each BEC category. Interestingly, $85 \%$ of patients were receiving ICS in the persistently high group, suggesting that ICS use is insufficient to lower BECs to $\leq 300$ cells $/ \mu \mathrm{L}$ for these patients. We also did not evaluate the prevalence of eosinophilic esophagitis among BEC groups, despite its association with asthma, because of the diagnostic challenges and rarity of the condition. A variable that was not available for analysis in the data sets was the time of day of BEC measurement. Circadian variations have been observed for BECs. ${ }^{39,40}$ The magnitude of daily variation is modest; therefore, the number of instances where the time of day made the difference between a value above or below 300 cells $/ \mu \mathrm{L}$ is likely small. Moreover, geometric mean BECs at the index date were $125.9 \pm 2.0$ cells $/ \mu \mathrm{L}$ in the never high group and $501.2 \pm 1.6$ cells $/ \mu \mathrm{L}$ in the persistently high group, indicating that measurements in these groups were generally not close to the 300 cells $/ \mu \mathrm{L}$ threshold. The group most likely to be affected were patients in the intermittently high group, for whom variability in measurement is expected. 


\section{Conclusion}

These data validate the use of blood eosinophil measurements to characterize a patient population at increased risk for severe asthma exacerbations. The consistency in risk elevation between the persistently high and intermittently high groups suggests that in patients with a single or multiple BEC measurements, 1 or more elevated BEC is sufficient to characterize a patient as having eosinophilic asthma, thus affirming the validity of categorizing patients in clinical practice, clinical trials, and real-world studies using the highest recorded BEC. Conversely, a single eosinophil measurement $\leq 300$ cells $/ \mu \mathrm{L}$ cannot rule out the potential of having eosinophilic asthma. For these patients, additional measurement of BECs in clinical practice is needed to increase the identification and appropriate management of patients with eosinophilic asthma.

\section{Abbreviations}

BEC, blood eosinophil count; COPD, chronic obstructive pulmonary disease; CPRD, Clinical Practice Research Datalink; ED, emergency department; EMR, electronic medical record; GINA, Global Initiative for Asthma; HCRU, health care resource utilization; ICS, inhaled corticosteroid; NHANES, National Health and Nutrition Examination Survey; OCS, oral corticosteroid; OPCRD, Optimum Patient Care Research Database; RDAC, risk domain asthma control; SABA, short-acting $\beta 2$-agonist; SMD, standardized mean difference; UK, United Kingdom; US, United States.

\section{Ethics Approval}

The study protocol was approved by the Anonymised Data Ethics Protocols and Transparency Committee (approval number, ADEPT1919) and the CPRD Independent Scientific Advisory Committee (ISAC approval number 19_229). The study was registered with the European Union electronic Register of Post-Authorisation Studies (registration number, EUPAS31500).

\section{Acknowledgments}

Writing and editing support, including preparation of the draft manuscript under the direction and guidance of the authors, incorporating author feedback, and manuscript submission, was provided by Crystal Murcia, PhD (CiTRUS Healthcare Communications Group). This support was funded by AstraZeneca (Gaithersburg, Maryland).

\section{Author Contributions}

Trung N Tran, Marjan Kerkhof, Victoria Carter, and David B Price were involved in the conception and design of the study; analysis and interpretation of the data; critical review of manuscript drafts; and approval of submitted version. The authors agreed on submission of the manuscript to this journal, have reviewed and agreed on all versions of the article throughout the submission process, and take responsibility and accountability for the content of the article.

\section{Funding}

This work was supported by AstraZeneca. A named author is an employee of AstraZeneca; therefore, AstraZeneca was involved in the study design; collection, analysis, and interpretation of data; and the development and review of the manuscript. The decision to submit the manuscript for publication was made by the authors.

\section{Disclosure}

Trung N Tran is an employee of AstraZeneca. Marjan Kerkhof was an employee of the Observational and Pragmatic Research Institute at the time of the study. Victoria Carter reports grants from Observational and Pragmatic Research Institute, during the conduct of the study. David B Price has board membership with Amgen, AstraZeneca, Boehringer Ingelheim, Chiesi, Circassia, Mylan, Mundipharma, Novartis, Regeneron Pharmaceuticals, Sanofi Genzyme, Teva Pharmaceuticals, Thermofisher, Zentiva (Sanofi Generics); consultancy agreements with Airway Vista Secretariat, Amgen, AstraZeneca, Boehringer Ingelheim, Chiesi, EPG Communication Holdings Ltd, FIECON Ltd, Fieldwork International, GlaxoSmithKline, Mylan, Mundipharma, Novartis, OM Pharma SA, PeerVoice, Phadia AB, Pfizer, Strategic North Limited, Synapse Research Management Partners S.L, Talos Health Solutions, Teva Pharmaceuticals, Theravance and WebMD Global LLC; grants and unrestricted funding for investigator-initiated studies (conducted through Observational and Pragmatic Research Institute Pte Ltd) from AKL Research and Development Ltd, AstraZeneca, Boehringer Ingelheim, British Lung Foundation, Chiesi, Circassia, Mylan, Mundipharma, Novartis, Pfizer, Regeneron Pharmaceuticals, Respiratory Effectiveness Group, Sanofi Genzyme, Teva Pharmaceuticals, Theravance, UK National Health Service; payment for lectures/speaking engagements from AstraZeneca, Boehringer Ingelheim, 
Chiesi, Cipla, GlaxoSmithKline, Kyorin, Merck, Mylan, Mundipharma, Novartis, Regeneron Pharmaceuticals, Sanofi Genzyme, Teva Pharmaceuticals; payment for the development of educational materials from Mundipharma, Novartis; payment for travel/accommodation/meeting expenses from AstraZeneca, Boehringer Ingelheim, Mundipharma, Mylan, Novartis, Thermofisher; funding for patient enrolment or completion of research from Novartis; stock/stock options from AKL Research and Development Ltd which produces phytopharmaceuticals; owns 92.61\% of Observational and Pragmatic Research Institute Pte Ltd (Singapore), owns 74\% of the social enterprise Optimum Patient Care Ltd (Australia and UK) and $74 \%$ of Observational and Pragmatic Research Institute Pte Ltd (Singapore); 5\% shareholding in Timestamp which develops adherence monitoring technology; is peer reviewer for grant committees of the Efficacy and Mechanism Evaluation programme, and Health Technology Assessment; and was an expert witness for GlaxoSmithKline. The authors report no other conflicts of interest in this work.

\section{References}

1. Agache I, Beltran J, Akdis C, et al. Efficacy and safety of treatment with biologicals (benralizumab, dupilumab, mepolizumab, omalizumab and reslizumab) for severe eosinophilic asthma. A systematic review for the EAACI Guidelines - recommendations on the use of biologicals in severe asthma. Allergy. 2020;75(5):1023-1042. doi:10.1111/all.14221

2. Global Initiative for Asthma. Global strategy for asthma management and prevention; 2020. Available from: www.ginasthma.org. Accessed November 2, 2020.

3. Lee LK, Ramakrishnan K, Safioti G, Ariely R, Schatz M. Asthma control is associated with economic outcomes, work productivity and health-related quality of life in patients with asthma. BMJ Open Respir Res. 2020;7(1):e000534. doi:10.1136/bmjresp-2019-000534

4. Castillo JR, Peters SP, Busse WW. Asthma exacerbations: pathogenesis, prevention, and treatment. J Allergy Clin Immunol Pract. 2017;5 (4):918-927. doi:10.1016/j.jaip.2017.05.001

5. Sundh J, Wireklint P, Hasselgren M, et al. Health-related quality of life in asthma patients - a comparison of two cohorts from 2005 and 2015. Respir Med. 2017;132:154-160. doi:10.1016/j.rmed.2017.10.010

6. Price DB, Trudo F, Voorham J, et al. Adverse outcomes from initiation of systemic corticosteroids for asthma: long-term observational study. J Asthma Allergy. 2018;11:193-204. doi:10.2147/JAA.S176026

7. Voorham J, Xu X, Price DB, et al. Healthcare resource utilization and costs associated with incremental systemic corticosteroid exposure in asthma. Allergy. 2019;74(2):273-283. doi:10.1111/all.13556

8. Bateman ED, Buhl R, O'Byrne PM, et al. Development and validation of a novel risk score for asthma exacerbations: the risk score for exacerbations. J Allergy Clin Immunol. 2015;135(6):1457-1464 e1454. doi:10.1016/j.jaci.2014.08.015

9. Yii ACA, Tan JHY, Lapperre TS, et al. Long-term future risk of severe exacerbations: distinct 5-year trajectories of problematic asthma. Allergy. 2017;72(9):1398-1405. doi:10.1111/all.13159
10. DiMango E, Rogers L, Reibman J, et al. Risk factors for asthma exacerbation and treatment failure in adults and adolescents with well-controlled asthma during continuation and step-down therapy. Ann Am Thorac Soc. 2018;15(8):955-961. doi:10.1513/ AnnalsATS.201711-886OC

11. Kuruvilla ME, Lee FE, Lee GB. Understanding asthma phenotypes, endotypes, and mechanisms of disease. Clin Rev Allergy Immunol. 2019;56(2):219-233. doi:10.1007/s12016-018-8712-1

12. Nelson RK, Bush A, Stokes J, Nair P, Akuthota P. Eosinophilic asthma. $J$ Allergy Clin Immunol Pract. 2020;8(2):465-473. doi:10.1016/j.jaip.2019.11.024

13. Tran TN, Khatry DB, Ke X, Ward CK, Gossage D. High blood eosinophil count is associated with more frequent asthma attacks in asthma patients. Ann Allergy Asthma Immunol. 2014;113(1):19-24. doi:10.1016/j.anai.2014.04.011

14. Zeiger RS, Schatz M, Li Q, et al. High blood eosinophil count is a risk factor for future asthma exacerbations in adult persistent asthma. $J$ Allergy Clin Immunol Pract. 2014;2(6):741-750. doi:10.1016/j.jaip.2014.06.005

15. Price DB, Rigazio A, Campbell JD, et al. Blood eosinophil count and prospective annual asthma disease burden: a UK cohort study. Lancet Respir Med. 2015;3(11):849-858. doi:10.1016/S2213-2600(15) 00367-7

16. Zeiger RS, Schatz M, Li Q, et al. The association of blood eosinophil counts to future asthma exacerbations in children with persistent asthma. J Allergy Clin Immunol Pract. 2015;3(2):283-287 e284. doi:10.1016/j.jaip.2014.10.009

17. Price D, Wilson AM, Chisholm A, et al. Predicting frequent asthma exacerbations using blood eosinophil count and other patient data routinely available in clinical practice. $J$ Asthma Allergy. 2016;9:1-12. doi:10.2147/JAA.S97973

18. Zeiger RS, Schatz M, Dalal AA, et al. Blood eosinophil count and outcomes in severe uncontrolled asthma: a prospective study. $J$ Allergy Clin Immunol Pract. 2017;5(1):144-153 e148. doi:10.1016/j.jaip.2016.07.015

19. Kerkhof M, Tran TN, van den Berge M, et al. Association between blood eosinophil count and risk of readmission for patients with asthma: historical cohort study. PLoS One. 2018;13(7):e0201143. doi:10.1371/journal.pone.0201143

20. Suruki RY, Daugherty JB, Boudiaf N, Albers FC. The frequency of asthma exacerbations and healthcare utilization in patients with asthma from the UK and USA. BMC Pulm Med. 2017;17(1):74. doi:10.1186/s12890-017-0409-3

21. Kerkhof M, Tran TN, Soriano JB, et al. Healthcare resource use and costs of severe, uncontrolled eosinophilic asthma in the UK general population. Thorax. 2018;73(2):116-124. doi:10.1136/thoraxjnl2017-210531

22. Fleming L, Tsartsali L, Wilson N, Regamey N, Bush A. Sputum inflammatory phenotypes are not stable in children with asthma. Thorax. 2012;67(8):675-681. doi:10.1136/thoraxjnl-2011-201 064

23. Spector SL, Tan RA. Is a single blood eosinophil count a reliable marker for "eosinophilic asthma?". J Asthma. 2012;49(8):807-810. doi:10.3109/02770903.2012.713428

24. Kupczyk M, Dahlen B, Sterk PJ, et al. Stability of phenotypes defined by physiological variables and biomarkers in adults with asthma. Allergy. 2014;69(9):1198-1204. doi:10.1111/all.12445

25. Mathur SK, Fichtinger PS, Evans MD, Schwantes EA, Jarjour NN. Variability of blood eosinophil count as an asthma biomarker. Ann Allergy Asthma Immunol. 2016;117(5):551-553. doi:10.1016/j. anai.2016.08.010

26. Silkoff PE, Laviolette M, Singh D, et al. Longitudinal stability of asthma characteristics and biomarkers from the Airways Disease Endotyping for Personalized Therapeutics (ADEPT) study. Respir Res. 2016;17(1):43. doi:10.1186/s12931-016-0360-5 
27. Herrett E, Gallagher AM, Bhaskaran K, et al. Data resource profile: Clinical Practice Research Datalink (CPRD). Int $J$ Epidemiol. 2015;44(3):827-836. doi:10.1093/ije/dyv098

28. Global Initiative for Asthma. Global Strategy for Asthma Management and Prevention; 2018. Available from: www. ginasthma.org. Accessed November 9, 2020.

29. Global Initiative for Asthma. Global Strategy for Asthma Management and Prevention; 2019. Available from: www. ginasthma.org. Accessed November 9, 2020.

30. Reddel HK, Taylor DR, Bateman ED, et al. An official American Thoracic Society/European Respiratory Society statement: asthma control and exacerbations: standardizing endpoints for clinical asthma trials and clinical practice. Am J Respir Crit Care Med. 2009;180(1):59-99. doi:10.1164/rccm.200801-060ST

31. Steven K, Neville RG, Hoskins G, Sullivan FM, Drummond N, Alder EM. The RCP's 'Three Key Questions' for asthma: review of practical use. $\mathrm{Br} J$ Community Nurs. 2002;7(6):300-303. doi:10.12968/bjen.2002.7.6.10474

32. Colice G, Chisholm A, Dima AL, et al. Performance of database-derived severe exacerbations and asthma control measures in asthma: responsiveness and predictive utility in a UK primary care database with linked questionnaire data. Pragmat Obs Res. 2018;9:29-42. doi:10.2147/POR.S151615

33. Faraone SV. Interpreting estimates of treatment effects: implications for managed care. P T. 2008;33(12):700-711.

34. Ricciardolo FLM, Levra S, Sprio AE, et al. A real-world assessment of asthma with chronic rhinosinusitis. Ann Allergy Asthma Immunol. 2020;125(1):65-71. doi:10.1016/j.anai.2020.03.004
35. Volmer T, Effenberger T, Trautner C, Buhl R. Consequences of long-term oral corticosteroid therapy and its side-effects in severe asthma in adults: a focused review of the impact data in the literature. Eur Respir J. 2018;52(4):1800703. doi:10.1183/13993003.007032018

36. Pavord ID, Mathieson N, Scowcroft A, Pedersini R, Isherwood G, Price D. The impact of poor asthma control among asthma patients treated with inhaled corticosteroids plus long-acting beta2-agonists in the United Kingdom: a cross-sectional analysis. NPJ Prim Care Respir Med. 2017;27(1):17. doi:10.1038/s41533-017-0014-1

37. Blakey JD, Gayle A, Slater MG, Jones GH, Baldwin M. Observational cohort study to investigate the unmet need and time waiting for referral for specialist opinion in adult asthma in England (UNTWIST asthma). BMJ Open. 2019;9(11):e031740. doi:10.1136/ bmjopen-2019-031740

38. Mahdavian M, Power BH, Asghari S, Pike JC. Effects of comorbidities on asthma hospitalization and mortality rates: a systematic review. Can Respir J. 2018;2018:6460379. doi:10.1155/2018/ 6460379

39. Durrington HJ, Gioan-Tavernier GO, Maidstone RJ, et al. Time of day affects eosinophil biomarkers in asthma: implications for diagnosis and treatment. Am J Respir Crit Care Med. 2018;198 (12):1578-1581. doi:10.1164/rccm.201807-1289LE

40. Coates S, Wang D, Pierscionek T, et al. Time- and race-specific haematological reference intervals for healthy volunteer trials: a retrospective analysis of pooled data from multiple Phase I trials. Front Pharmacol. 2020;11:314. doi:10.3389/fphar.2020.00314

\section{Publish your work in this journal}

The Journal of Asthma and Allergy is an international, peer-reviewed open-access journal publishing original research, reports, editorials and commentaries on the following topics: Asthma; Pulmonary physiology; Asthma related clinical health; Clinical immunology and the immunological basis of disease; Pharmacological interventions and new therapies. The manuscript management system is completely online and includes a very quick and fair peer-review system, which is all easy to use. Visit http://www.dovepress.com/testimonials.php to read real quotes from published authors. 